\title{
Gene delivery into hepatic cells with ternary complexes of plasmid DNA, cationic liposomes and apolipoprotein E-derived peptide
}

\author{
YOSHIYUKI HATTORI, YUTA NAKAGAWA and HIRAKU ONISHI \\ Department of Drug Delivery Research, Hoshi University, Tokyo 142-8501, Japan
}

Received April 4, 2019; Accepted July 12, 2019

DOI: $10.3892 /$ etm.2019.7863

\begin{abstract}
Cationic liposomes containing a cationic lipid, such as 1,2-dioleoyl-3-trimethylammonium-propane (DOTAP), have often been used for the transduction of plasmid DNA (pDNA) in vivo. However, such liposomes induce gene expression primarily in the lungs after intravenous injection. To improve the delivery of cationic liposomes/pDNA complexes (pDNA lipoplexes) to the liver by intravenous administration, the current study synthesized two apolipoprotein $\mathrm{E}$ (ApoE)-derived peptides, dApoE-R9 and ApoE-F-R9, for liver targeting via certain ApoE receptors, including the low-density lipoprotein receptor. Ternary complexes of pDNA, cationic liposomes and ApoE-R9 peptide were also prepared. After in vitro transfection, ternary complexes with DOTAP/1,2dioleoyl-sn-glycero-3-phosphoethanolamine (DOPE) liposomes exhibited high transfection activity in HepG2 cells compared with DOTAP/cholesterol (Chol) liposomes. In particular, ternary complexes with dApoE-R9 exhibited high transfection activity in cells compared with ApoE-F-R9. However, in vivo transfection studies revealed that ternary complexes with DOTAP/DOPE liposomes and dApoE-R9 did not increase gene expression in the liver compared with DOTAP/DOPE lipoplexes. In contrast, ternary complexes with DOTAP/Chol liposomes and dApoE-R9 increased gene expression in the liver compared with DOTAP/Chol lipoplexes. The results demonstrated that the in vivo optimal liposomal formulation in ternary complexes with ApoE-R9 peptide for liver delivery were different from those that were in vitro.
\end{abstract}

\section{Introduction}

Gene therapy has become an increasingly important strategy for treating various hepatic diseases (1). The liver is an important organ with potential therapeutic targets,

Correspondence to: Professor Yoshiyuki Hattori, Department of Drug Delivery Research, Hoshi University, 2-4-41, Ebara, Shinagawa-ku, Tokyo 142-8501, Japan

E-mail: yhattori@hoshi.ac.jp

Key words: cationic liposome, apolipoprotein E, plasmid DNA, liver-targeting including cholesterol biosynthesis, fibrosis, and hepatitis. For example, in hepatic gene therapy, mutated genes that cause hepatic diseases can be replaced by the transduction of mutation-corrected genes into hepatocytes. However, a major requirement for hepatic gene therapy is the efficient delivery of DNA into hepatocytes by systemic injection (2). Based on the type of vector used for gene delivery, vectors can be divided into viral and non-viral vectors $(3,4)$. Non-viral vectors are less efficient but safer than viral vectors; therefore, non-viral vectors are an attractive alternative method for gene therapy. Cationic liposomes are an example of a non-viral vector, and among them, cationic liposomes composed of cationic lipids, such as 1,2-dioleoyl-3-trimethylammonium-propane (DOTAP), have often been used for the in vivo transduction of plasmid DNA (pDNA) $(5,6)$. However, the positive charge of cationic liposome/pDNA complexes (pDNA lipoplexes) leads to interactions with albumin and other serum proteins (7), and the agglutinates contribute to high entrapment of pDNA lipoplexes in the highly extended lung capillaries (8), resulting in expression mostly in the lung when injected intravenously. Therefore, it is necessary to develop a delivery system to efficiently target pDNA lipoplexes to the liver.

Receptor-mediated targeting is a promising approach to deliver pDNA lipoplexes to hepatocytes. Hepatocytes express the asialoglycoprotein receptor on their surface, which recognizes the galactose residue of asialoglycoproteins. Therefore, galactose-modified cationic liposomes have been utilized for liver-targeting pDNA delivery (9). Furthermore, hepatocytes play a key role in lipid and lipoprotein metabolism, and some apolipoproteins, such as apolipoprotein B (ApoB) and apolipoprotein $\mathrm{E}$ (ApoE), serve as ligands for the uptake of lipoprotein by hepatocytes (10). ApoE is a constituent of chylomicron, very low-density lipoprotein (VLDL), low-density lipoprotein (LDL), and high-density lipoprotein (11), and it is a high-affinity ligand for several ApoE receptors such as LDL receptor, VLDL receptor, and lipoprotein receptor-related protein 1 (LRP1), which have been shown to be essential for hepatic clearance of VLDL and remnant lipoprotein (12). It has been reported that ApoE can bind to liposomes (13), and it mediated the uptake of liposomes by hepatocytes in mice (14). Tamaru et al (15) found that recombinant human ApoE3-modification increases the uptake of pDNA entrapped in liposomes in neuroblastoma Neuro2a cells. However, recombinant ApoE protein is too large $(34 \mathrm{kDa})$ to use as a ligand for the liver-targeting of pDNA lipoplexes. Previous studies 
showed that dApoE peptide containing amino acid sequence 141-151 of human ApoE in a tandem dimer $(16,17)$ and ApoE fragment peptide (ApoE-F) containing amino acid sequence 151-173 of human ApoE4 (18) bind to cells expressing the LDL receptor. Therefore, we speculated that ApoE-derived peptide-modified pDNA lipoplexes may improve pDNA delivery to the liver after systemic injection.

In this study, we synthesized two types of ApoE-derived peptide, dApoE-R9 and ApoE-F-R9, which included nine arginine residues at the terminus of the peptides, for interaction with pDNA, and evaluated transfection efficiency in vitro and in vivo by ternary complexes with pDNA, cationic liposomes, and ApoE-R9 peptide. To the best of our knowledge, there are no reports on the application of ApoE-derived peptides for pDNA delivery into hepatic cells. Here, we found that ternary complexes increased the transfection efficiency in hepatic cells by inclusion of the ApoE-R9 peptide, although the in vivo optimal liposomal formulation in ternary complexes with the ApoE-R9 peptide were different from the in vitro one.

\section{Materials and methods}

Materials. 1,2-Dioleoyl-3-trimethylammonium-propane methyl sulfate salt (DOTAP) was obtained from Avanti Polar Lipids Inc. 1,2-Dioleoyl-sn-glycero-3-phosphoethanolamine (DOPE, COATSOME ME-8181) was obtained from NOF Co. Ltd. Cholesterol (Chol) was purchased from Wako Pure Chemical Industries, Ltd. Quaser670 carboxylic acid was obtained from Biosearch Technologies, Inc. All other chemicals were of the finest grade available.

Synthesis of ApoE-derived peptide. dApoE peptide contained amino acid sequence 141-151 of human ApoE in a tandem dimer comprising WG-(LRKLRKRLLR) ${ }_{2}-\mathrm{NH}_{2}(16,17)$. The ApoE fragment (ApoE-F) peptide contained the amino acid sequence of the binding domain of human ApoE4 (amino acids 151-173) comprising YLRVRLASHLRKLRKRLLRDADDLY (18). For the detection of ApoE-derived peptides, dApoE and ApoE-F peptides were labeled with Quaser670 via three glycine residues as a spacer at the $\mathrm{N}$-terminus of $\mathrm{dApoE}$ and $\mathrm{C}$-terminus of ApoE-F [Quaser670-labeled dApoE (Q-dApoE) and Quaser670-labeled ApoE-F (Q-ApoE-F), GenScript Biotech Corp., Piscataway, NJ, USA] (Table I). Quasar670 is an indocarbocyanine that exhibits fluorescence in the red region of the visible spectrum. The purities of Q-dApoE and Q-ApoE-F were 79.3 and $71.7 \%$, respectively, by HPLC analysis, and their molecular weights were 3,578.56 and 3,920.47, respectively, by MALDI-TOF mass spectrometry. For the interaction of ApoE-derive peptides with pDNA, nine arginine residues were included at the $\mathrm{N}$-terminus of $\mathrm{dApoE}$ and $\mathrm{C}$-terminus of ApoE-F via three glycine residues as a spacer (dApoE-R9 and ApoE-F-R9; Medical \& Biological Laboratories Co., Ltd.) (Table I). The purities of dApoE-R9 and ApoE-F-R9 were 96.9 and $99.7 \%$, respectively, by HPLC analysis, and their molecular weights were 4505.25 and 4718.55 , respectively, by MALDI-TOF mass spectrometry.

Cell culture. Human hepatoblastoma HepG2 cells were donated by Prof. Kei-ichi Ozaki (Education and Research Center for
Pharmaceutical Sciences, Osaka University of Pharmaceutical Sciences, Osaka, Japan). Human lung adenocarcinoma A549 cells were kindly provided by OncoTherapy Science, Inc.

HepG2 cells were cultured in Dulbecco's modified Eagle's medium (DMEM) with $10 \%$ heat-inactivated fetal bovine serum (FBS) and kanamycin $(100 \mu \mathrm{g} / \mathrm{ml})$ in a humidified atmosphere containing $5 \% \mathrm{CO}_{2}$ at $37^{\circ} \mathrm{C}$. A549 cells were grown in RPMI-1640 medium supplemented with $10 \%$ heat-inactivated FBS and kanamycin $(100 \mu \mathrm{g} / \mathrm{ml})$ at $37^{\circ} \mathrm{C}$ in a $5 \% \mathrm{CO}_{2}$ humidified atmosphere.

Cellular uptake of ApoE-derived peptides. HepG2 cells were plated into $35-\mathrm{mm}$ culture dishes at a density of $3 \times 10^{5}$ cells $24 \mathrm{~h}$ prior to each experiment. Quaser670, Q-dApoE, and Q-ApoE-F were diluted in $1 \mathrm{ml}$ of culture medium to final concentrations of 1,10 , and $10 \mu \mathrm{g} / \mathrm{ml}(2,2.8$, and $2.6 \mu \mathrm{M})$, respectively, and they were incubated with cells for $3 \mathrm{~h}$. After the incubation, the cells were fixed with $10 \%$ formaldehyde. The localization of Quaser670, Q-dApoE, and Q-ApoE-F was visualized using an Eclipse TS100-F microscope (Nikon).

Biodistribution of ApoE-derived peptides in mice. All animal experiments were conducted in accordance with the 'Guide for the Care and Use of Laboratory Animals' adopted by the Institutional Animal Care and Use Committee of Hoshi University (Tokyo, Japan) (which is accredited by the Ministry of Education, Culture, Sports, Science, and Technology, Japan). Ethical approval for this study was obtained from the Institutional Animal Care and Use Committee of Hoshi University (Permission no. 30-072). A total of six female BALB/c mice (18-20 g, 8 weeks of age; Sankyo Labo Service Corp., Tokyo, Japan) were housed in a temperature- $\left(24^{\circ} \mathrm{C}\right)$ and humidity-(55\%) controlled room with a $12 \mathrm{~h}$ light/dark cycle (lights on at 8:00 a.m.) with ad libitum access to food and water.

Q-dApoE [20 or $100 \mu \mathrm{g}$ (5.6 or $27.9 \mathrm{nmol})]$ or Q-ApoE-F [20 or $100 \mu \mathrm{g}(5.1$ or $25.5 \mathrm{nmol})]$ were administered intravenously via the lateral tail vein into female BALB/c mice $(n=1$ for 20 and $100 \mu \mathrm{g}$ ApoE peptide, respectively). As a control, Quaser670 [2 or $10 \mu \mathrm{g}$, (4.0 or $20.1 \mathrm{nmol})$ ] was administered intravenously via the lateral tail vein into mice $(n=1$ for 2 and $10 \mu \mathrm{g}$ Quaser670, respectively). Ten or $60 \mathrm{~min}$ after the injection, mice were sacrificed, and Quaser670 fluorescence imaging of the tissues was performed using a NightOWL LB981 NC100 system (Berthold Technologies). In Quaser670 fluorescence imaging, the excitation and emission filters were set at $630 / 20$ and $680 / 30 \mathrm{~nm}$, respectively. The exposure time for fluorescence was $1 \mathrm{sec}$. A grayscale body-surface reference image was collected using a NightOWL LB981 CCD camera. The images were analyzed using IndiGo2 software (version 2.0.1.0) provided with the in vivo imaging system (Berthold Technologies). The tissues after fluorescence imaging were frozen on dry ice and sliced into $16 \mu \mathrm{m}$ sections. The localization of Quaser670, Q-dApoE, and Q-ApoE-F was examined using an Eclipse TS100-F microscope.

Preparation of plasmid DNA. The pCMV-luc plasmid encoding the firefly luciferase gene under the control of the cytomegalovirus (CMV) promoter was constructed as described previously (19). A protein-free preparation of pDNA 
Table I. Apo E-derived peptides used in the present study.

Peptide

Sequence

Q-dApoE

dApoE-R9

Q-ApoE-F

ApoE-F-R9

\section{Quasar670-GGGWGLRKLRKRLLRLRKLRKRLLR- $\mathrm{NH}_{2}$ RRRRRRRRRGGGWGLRKLRKRLLRLRKLRKRLLR- $\mathrm{NH}_{2}$ YLRVRLASHLRKLRKRLLRDADDLYGGG-Lys-Quasar670-CONH YLRVRLASHLRKLRKRLLRDADDLYGGGRRRRRRRRR}

Underlined amino acids indicate the spacers between the ApoE-derived peptide and 9 arginine residues or Quaser670. Bold sequences in ApoE-derived peptides indicate the receptor binding domain (LRKLRKRLLR). A, alanine; D, aspartic acid; G, glycine; H, histidine; K, lysine; L, leucine; R, arginine; S, serine; V, valine; W, tryptophan; Y, tyrosine; Q, Quaser670; ApoE, apolipoprotein E.

was purified after alkaline lysis using a QIAGEN Plasmid Maxi Kit (Qiagen, Hilden, Germany).

Preparation of cationic liposomes, pDNA lipoplexes, and ternary complexes. Cationic liposomes (LP-DOTAP/Chol and LP-DOTAP/DOPE) were prepared from DOTAP:Chol or DOTAP:DOPE at a molar ratio of 1:1 using a dry-film method (20). Briefly, all lipids were dissolved in chloroform, which was removed by evaporation. The thin film was hydrated with water at $60^{\circ} \mathrm{C}$ by vortex mixing and sonication. The particle size distributions and $\zeta$-potentials were determined by the dynamic light scattering method (ELS-Z2; Otsuka Electronics, Osaka, Japan) at $25^{\circ} \mathrm{C}$ after diluting the dispersion to an appropriate volume with water.

Cationic liposome/pDNA complexes (pDNA lipoplexes) were prepared by mixing pDNA with cationic liposomes at a charge ratio (-:+) of 1:4, as reported previously (21). Binary complexes of pDNA and ApoE-R9 peptide were prepared by mixing pDNA with dApoE-R9 or ApoE-F-R9 at charge ratios (-:+) of $1: 1,1: 2$, and $1: 3(3.2,6.5$, and $9.7 \mu \mathrm{g}$ dApoE-R9 or $3.4,6.8$, and $10.2 \mu \mathrm{g}$ ApoE-F-R9 for $2 \mu \mathrm{g}$ pDNA, respectively). Ternary complexes of pDNA, cationic liposomes, and ApoE-R9 peptide were prepared by mixing ApoE-R9 peptide with cationic liposomes, followed by mixing with pDNA at charge ratios (-:+:+) of pDNA:cationic liposomes:ApoE-R9 peptide of $1: 4: 1,1: 4: 2$, and $1: 4: 3$. The complexes were shaken gently and stood for $15 \mathrm{~min}$ at room temperature. The charge ratio (-:+) of pDNA:Cationic liposomes was expressed as the molar ratio of pDNA phosphate to DOTAP. The charge ratio (-:+) of pDNA:dApoE-R9 or pDNA:ApoE-F-R9 was expressed as the molar ratio of pDNA phosphate to arginine residue at the terminus of the ApoE-R9 peptides ( 9 arginine residues per peptide).

Accessibility of pDNA in binary and ternary complexes. pDNA association with ApoE-R9 peptide or cationic liposomes was analyzed using an exclusion assay with SYBR ${ }^{\circledR}$ Green I Nucleic Acid Gel Stain (Takara Bio Inc.). Binary complexes of pDNA and ApoE-R9 peptide were formed at charge ratios (-:+) of 1:1, 1:2, and 1:3. Ternary lipoplexes of pDNA, cationic liposome, and ApoE-R9 peptide were formed at charge ratios (-:+:+) of $1: 4: 1,1: 4: 2$, and $1: 4: 3$. The binary or ternary complexes of $0.5 \mu \mathrm{g}$ of pDNA in a volume of $100 \mu \mathrm{l}$ of Tris-HCl buffer ( $\mathrm{pH}$ 8.0) were mixed with $100 \mu \mathrm{l}$ of 5,000-fold diluted SYBR ${ }^{\circledR}$ Green I Nucleic Acid Gel Stain solution with
Tris- $\mathrm{HCl}$ buffer, and then incubated for $30 \mathrm{~min}$. Fluorescence was measured at an emission wavelength of $535 \mathrm{~nm}$ with an excitation wavelength of $485 \mathrm{~nm}$ using a fluorescence plate reader (ARVO X2; Perkin Elmer). As a control, the value of fluorescence obtained upon addition of free pDNA solution was set as $100 \%$. The amount of pDNA available to interact with the SYBR ${ }^{\circledR}$ Green I was expressed as a percentage of the control.

Luciferase activity in vitro. HepG2 and A549 cells were prepared by plating cells in a 6 -well plate $24 \mathrm{~h}$ prior to each experiment. pDNA lipoplexes of pCMV-Luc $(2 \mu \mathrm{g})$, binary complexes of pCMV-Luc $(2 \mu \mathrm{g})$ and ApoE-R9 peptide or ternary complexes of pCMV-Luc $(2 \mu \mathrm{g})$, cationic liposomes, and ApoE-R9 peptide were transfected into cells. Twenty-four hours after transfection, luciferase activity was measured as counts per second (cps) $/ \mu$ g protein using the luciferase assay system (PicaGene; Toyo Ink Manufacturing. Co., Ltd.) and bicinchoninic acid (BCA) reagent $\left(\right.$ Pierce $^{\mathrm{TM}}$ BCA Protein Assay kit; Pierce; Thermo Fisher Scientific, Inc.) as reported previously (22).

Cytotoxicity by ternary complexes. HepG2 cells were seeded in 96-well plates $24 \mathrm{~h}$ prior to transfection. Ternary complexes of pDNA, LP-DOTAP/DOPE, and ApoE-R9 peptide were formed at charge ratios (-:+:+) of 1:4:1, 1:4:2, and 1:4:3. Each ternary complex with $2 \mu \mathrm{g}$ of pDNA was diluted in $1 \mathrm{ml}$ of medium supplemented with $10 \%$ FBS, and then the mixture (100 $\mu \mathrm{l}$ ) was added to the cells at $50 \%$ confluency in the well. After a 24-h incubation period, cell numbers were determined using a Cell Counting Kit-8 (Dojindo Laboratories). Cell viability was expressed as relative to the absorbance at $450 \mathrm{~nm}$ of untransfected cells.

Transfection activity in vivo. pDNA lipoplexes with $30 \mu \mathrm{g}$ pCMV-Luc and cationic liposomes were prepared at a charge ratios (-:+) of 1:4, and ternary complexes with $30 \mu \mathrm{g}$ pCMV-Luc, cationic liposomes, and dApoE-R9 (145.5 $\mu \mathrm{g}$ for $30 \mu \mathrm{g}$ pDNA) were prepared at a charge ratio (-:+:+) of 1:4:3. The pDNA lipoplexes or ternary complexes with $30 \mu \mathrm{g}$ of pCMV-Luc were administered intravenously via the lateral tail vein into a total of 12 female BALB/c mice ( 8 weeks of age) ( $n=3$ for each the complex). At 24-h post-injection, mice were sacrificed by cervical dislocation, and tissues were removed for analysis. Three microliters of ice-cold reporter lysis buffer 


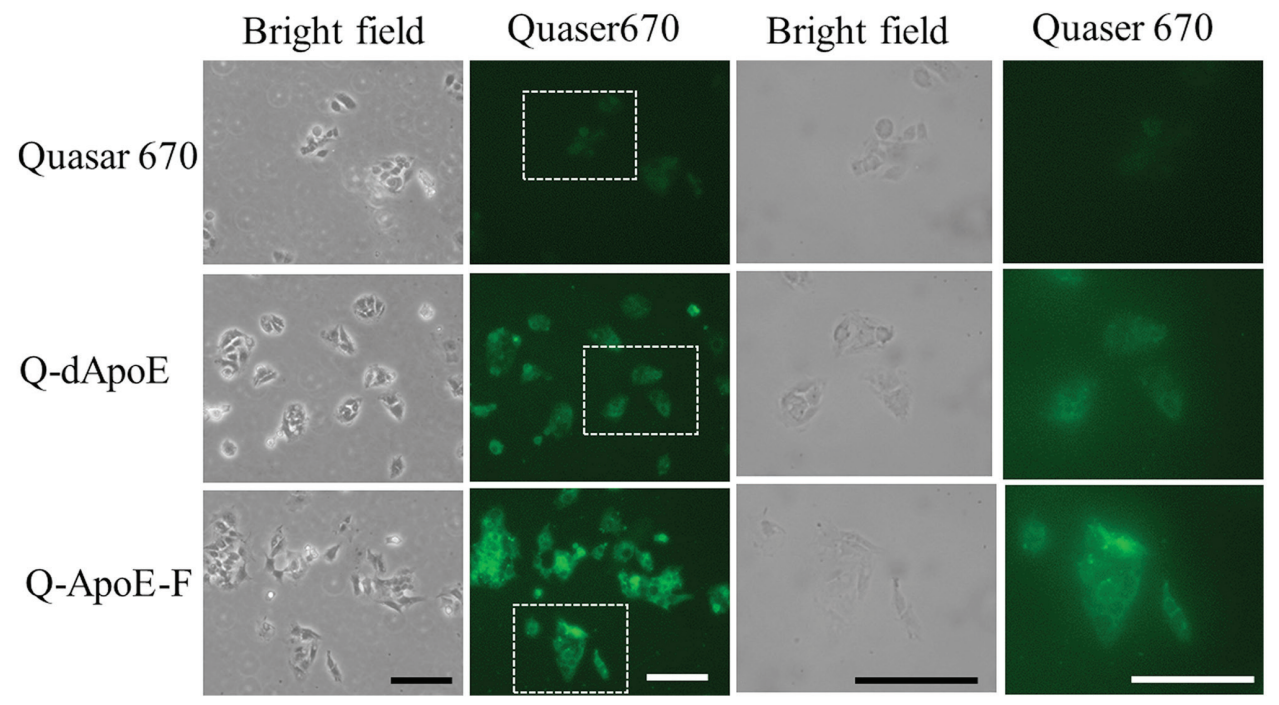

Figure 1. Intracellular localization of ApoE-derived peptide in HepG2 cells after incubation for $3 \mathrm{~h}$. Free Quaser670, Q-dApoE, and Q-ApoE-F were diluted in $1 \mathrm{ml}$ culture medium at final concentrations of 1,10 and $10 \mu \mathrm{g} / \mathrm{ml}(2,2.8$ and $2.6 \mu \mathrm{M})$, respectively, and then incubated with cells for $3 \mathrm{~h}$. Green signals indicate localization of Quaser670, Q-dApoE or Q-ApoE-F. White boxes indicate the enlarged panels presented in the right panels. Scale bar, $100 \mu \mathrm{m}$. ApoE, apolipoprotein E.

(Promega Corporation) per $1 \mathrm{mg}$ of tissue was added, and then homogenized immediately. The homogenate samples were centrifuged at $15,000 \mathrm{rpm}$ for $3 \mathrm{~min}$ at $4^{\circ} \mathrm{C}$. Aliquots of $10 \mu \mathrm{l}$ of the supernatants were mixed with $50 \mu 1$ of luciferase assay system (PicaGene), and counts per second (cps) were measured using a chemoluminometer (ARVOX2). The protein concentration of each supernatant was determined using a BCA protein assay (Microplate BCA Protein Assay kit-Reducing Agent Compatible; Pierce; Thermo Fisher Scientific, Inc.) with bovine serum albumin as the standard, and luciferase activity was calculated as cps/mg protein.

Statistical analysis. Data are presented as the mean + standard deviation of three independent experiments. The statistical significance of differences between mean values was determined by Student's t-test using GraphPad Prism 4.0 (GraphPad Software Inc.). Multiple measurement comparisons were performed by analysis of variance followed by one-way analysis of variance on ranks with post hoc Tukey-Kramer's test using GraphPad Prism 4.0. $\mathrm{P}<0.05$ was considered to indicate a statistically significant difference.

\section{Results and Discussion}

Uptake of ApoE-derived peptide in hepatic cells. First, to confirm the uptake of the ApoE-derived peptide in hepatic cells, we synthesized two types of Quaser670-labeled ApoE-derived peptides, Q-dApoE and Q-ApoE-F (Table I), and examined the localization of their peptides in HepG2 cells after a 3-h incubation. HepG2 cells are one of the most commonly used cell lines as hepatic cells. Both peptides were detected throughout the cytoplasm strongly and diffusively in most cells, although free Quaser670 was not taken up by the cells (Fig. 1), indicating that ApoE-derived peptides were effectively taken up by the cells.

Next, to investigate whether ApoE-derived peptides may be taken up into the liver, we injected Q-dApoE and Q-ApoE-F intravenously into mice and observed their biodistributions at 10 and 60 min after injection (Figs. 2 and 3). Free Quaser670 accumulated mainly in the liver and kidneys at 10 min after injection (Fig. 3); however, it was detected only in kidneys at 60 min (Figs. 2 and 3), indicating that free Quaser670 (MW 497.69) was rapidly excreted from the kidneys after intravenous injection. In contrast, Q-dApoE was detected mainly in the liver, spleen, and kidneys, and Q-ApoE-F was found in the liver and kidneys at $60 \mathrm{~min}$ after injection (Figs. 2 and 3), indicating that Q-dApoE and Q-ApoE-F were efficiently taken up via ApoE receptors by hepatocytes in the mouse liver, although some injected peptides were excreted from the kidneys due to their low molecular weight (less than $4,000)$. However, we could not confirm whether Q-dApoE and Q-ApoE-F were localized mainly in parenchymal or/and non-parenchymal cells of the liver. These results suggested that dApoE and ApoE-F may be useful as ligands for liver targeting.

Characterization of cationic liposomes and ternary complexes. For pDNA delivery with ApoE-derived peptides, we synthesized two further types of ApoE-derived peptides, dApoE-R9 and ApoE-F-R9 (Table I), which were conjugated with nine arginine residues for interaction with pDNA, and prepared ternary complexes of pDNA, cationic liposomes, and ApoE-R9 peptides. The selected cationic liposomes, DOTAP/Chol liposomes and DOTAP/DOPE liposomes, have often been used for pDNA transfection in previous studies (23-25). In addition, it has been shown that neutral helper lipids for cationic liposomal formulation significantly affected the transfection efficiency in vitro and in vivo $(26,27)$. Therefore, in this study, we used DOTAP as a cationic lipid, and DOPE or Chol as a neutral helper lipid, and prepared two types of cationic liposomes, LP-DOTAP/DOPE and LP-DOTAP/Chol for pDNA delivery. LP-DOTAP/DOPE consisted of DOTAP and DOPE at a molar ratio of 1:1, and LP-DOTAP/Chol consisted of DOTAP and Chol at a molar ratio of $1: 1$. 


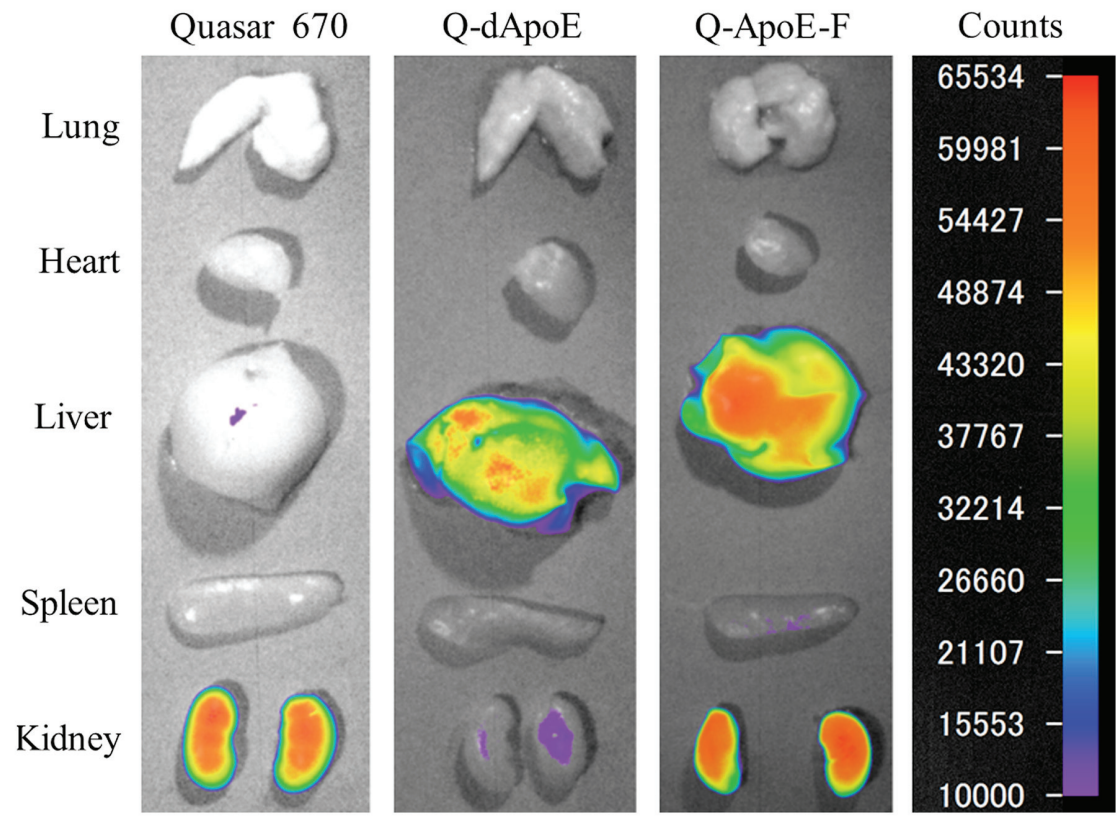

Figure 2. Biodistribution of ApoE-derived peptide in mice $1 \mathrm{~h}$ after intravenous injection. Q-dApoE or Q-ApoE-F (20 $\mu \mathrm{g})$ was administered intravenously to mice. As a control, Quaser670 $(2 \mu \mathrm{g})$ was administered intravenously. A total of $1 \mathrm{~h}$ after injection, mice were sacrificed and Quaser670 fluorescence imaging of the tissues was performed. Fluorescence intensity is illustrated by a color-coded scale (red is maximum, purple is minimum). ApoE, apolipoprotein E.
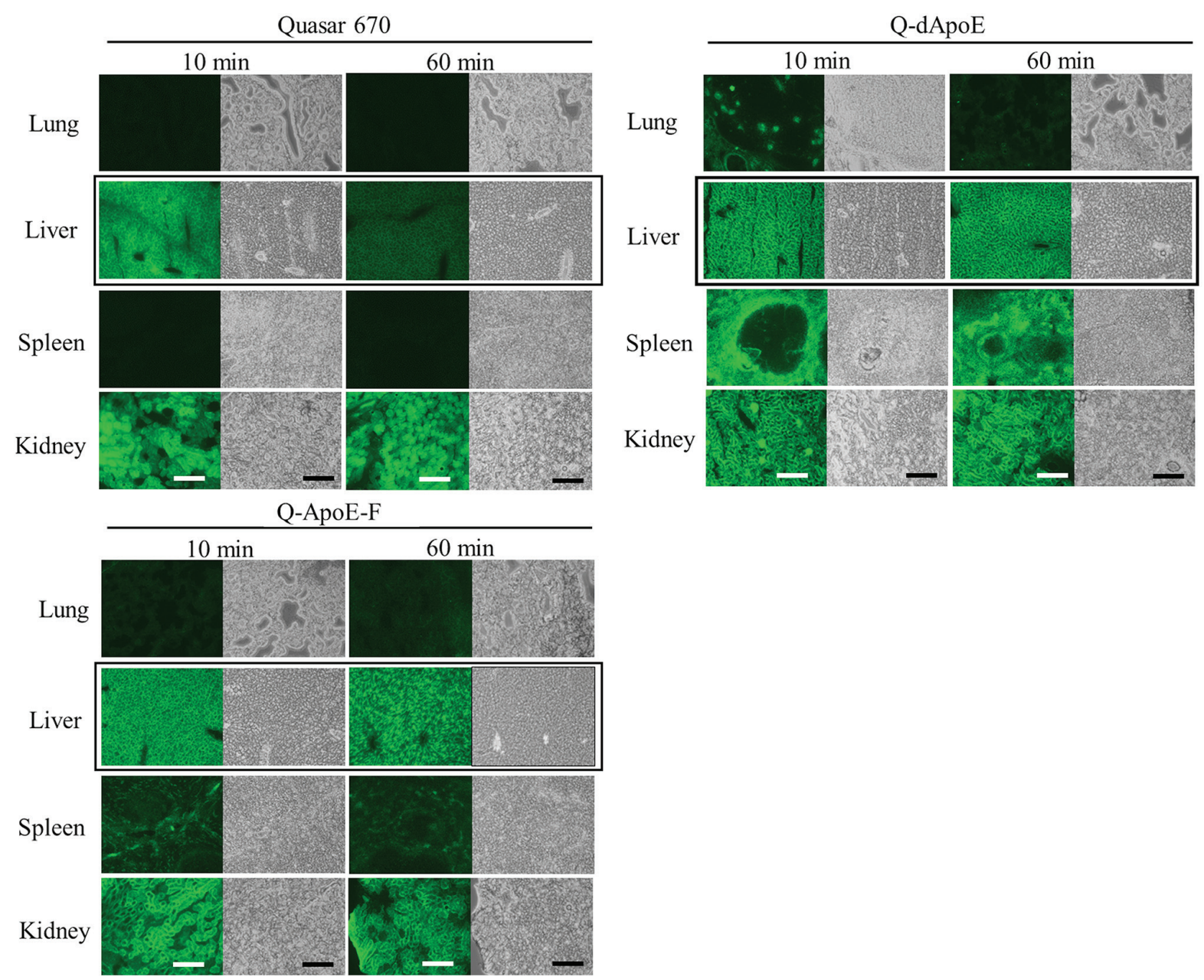

Figure 3. Biodistribution of ApoE-derived peptide in mice at 10 and 60 min after intravenous injection. Q-dApoE or Q-ApoE-F (100 $\mu \mathrm{g})$ was administered intravenously to mice. As a control, Quaser670 $(10 \mu \mathrm{g})$ was administered intravenously. A total of 10 or 60 min after injection, mice were sacrificed and tissues were frozen on dry ice and sliced into $16 \mu \mathrm{m}$ sections. The localization of Quaser670 was examined using a fluorescence microscope. Green signals indicated the localization of Quaser670, Q-dApoE or Q-ApoE-F. Black boxes indicate marked changes of accumulation in the liver. Scale bar, $200 \mu \mathrm{m}$. ApoE, apolipoprotein E. 
Table II. Particle size and $\zeta$-potential of ternary complexes with pDNA, cationic liposomes and ApoE-R9 peptides.

\begin{tabular}{|c|c|c|c|c|}
\hline Liposomes and lipoplexes & Charge ratio $(-:+:+)$ & $\operatorname{Size}^{\mathrm{a}}(\mathrm{nm})$ & PDI & $\zeta$-potential ${ }^{\mathrm{a}}(\mathrm{mV})$ \\
\hline LP-DOTAP/DOPE & - & $102.2 \pm 0.6$ & $0.22 \pm 0.01$ & $46.3 \pm 0.8$ \\
\hline pDNA:LP-DOTAP/DOPE & $1: 4: 0$ & $152.6 \pm 0.3$ & $0.19 \pm 0.00$ & $37.1 \pm 1.8$ \\
\hline pDNA:LP-DOTAP/DOPE:dApoE-R9 & $1: 4: 1$ & $142.5 \pm 1.7$ & $0.19 \pm 0.01$ & $41.9 \pm 0.4$ \\
\hline pDNA:LP-DOTAP/DOPE:dApoE-R9 & $1: 4: 2$ & $132.2 \pm 2.2$ & $0.18 \pm 0.01$ & $41.4 \pm 0.8$ \\
\hline pDNA:LP-DOTAP/DOPE:dApoE-R9 & $1: 4: 3$ & $134.4 \pm 0.6$ & $0.18 \pm 0.01$ & $38.0 \pm 2.5$ \\
\hline pDNA:LP-DOTAP/DOPE:ApoE-F-R9 & $1: 4: 1$ & $140.4 \pm 1.7$ & $0.16 \pm 0.02$ & $37.9 \pm 0.5$ \\
\hline pDNA:LP-DOTAP/DOPE:ApoE-F-R9 & $1: 4: 2$ & $132.0 \pm 0.8$ & $0.18 \pm 0.01$ & $40.7 \pm 0.8$ \\
\hline pDNA:LP-DOTAP/DOPE:ApoE-F-R9 & $1: 4: 3$ & $129.2 \pm 2.6$ & $0.18 \pm 0.02$ & $42.2 \pm 1.0$ \\
\hline LP-DOTAP/Chol & - & $104.4 \pm 0.8$ & $0.21 \pm 0.01$ & $47.7 \pm 0.6$ \\
\hline pDNA:LP-DOTAP/Chol & $1: 4: 0$ & $184.0 \pm 1.8$ & $0.18 \pm 0.01$ & $33.7 \pm 0.7$ \\
\hline pDNA:LP-DOTAP/Chol:dApoE-R9 & $1: 4: 1$ & $150.1 \pm 0.8$ & $0.16 \pm 0.00$ & $42.3 \pm 1.1$ \\
\hline pDNA:LP-DOTAP/Chol:dApoE-R9 & $1: 4: 2$ & $127.7 \pm 2.2$ & $0.19 \pm 0.01$ & $41.4 \pm 1.0$ \\
\hline pDNA:LP-DOTAP/Chol:dApoE-R9 & $1: 4: 3$ & $131.4 \pm 1.5$ & $0.19 \pm 0.01$ & $42.4 \pm 0.2$ \\
\hline pDNA:LP-DOTAP/Chol:ApoE-F-R9 & $1: 4: 1$ & $152.9 \pm 1.6$ & $0.17 \pm 0.01$ & $38.4 \pm 0.3$ \\
\hline pDNA:LP-DOTAP/Chol:ApoE-F-R9 & $1: 4: 2$ & $138.6 \pm 1.8$ & $0.17 \pm 0.01$ & $36.1 \pm 0.8$ \\
\hline pDNA:LP-DOTAP/Chol:ApoE-F-R9 & $1: 4: 3$ & $134.4 \pm 2.3$ & $0.17 \pm 0.00$ & $36.1 \pm 1.0$ \\
\hline
\end{tabular}

${ }^{a}$ In water. Data are presented as the mean \pm standard deviation $(n=3)$. PDI, polydispersity index. pDNA, plasmid DNA; DOTAP, 1,2-dioleoyl-3-trimethylammonium-propane methyl sulfate salt; DOPE, 1,2-dioleoyl-sn-glycero-3-phosphoethanolamine; Chol, cholesterol; ApoE, apolipoprotein E.

Next, we measured the particle size and $\zeta$-potential of the cationic liposomes, pDNA lipoplexes, and ternary complexes. The sizes of LP-DOTAP/DOPE and LP-DOTAP/Chol were approximately $100 \mathrm{~nm}$, and the $\zeta$-potentials were approximately 46-48 mV (Table II). When LP-DOTAP/DOPE and LP-DOTAP/Chol were mixed with pDNA, the sizes were 152 and $184 \mathrm{~nm}$, respectively, and the $\zeta$-potentials were approximately 37 and $34 \mathrm{mV}$, respectively. For formation of the ternary complexes, LP-DOTAP/DOPE or LP-DOTAP/Chol was mixed with dApoE-R9 or ApoE-F-R9, followed by mixing with pDNA at charge ratios (-:+:+) of pDNA:cationic liposome:ApoE-R9 peptide from 1:4:1 to 1:4:3 (Table II). Here, in order to make the number of moles of ApoE peptides equal between the ternary complexes with dApoE-R9 and ApoE-F-R9, we calculated the charge ratio (-:+) of pDNA:dApoE-R9 or pDNA:ApoE-F-R9 as the molar ratio of pDNA phosphate to arginine residue at a terminus of the ApoE-R9 peptides ( 9 arginine residues per peptide) although both dApoE-R9 and ApoE-F-R9 contained positively charged amino acids in the sequence of ApoE (the net charges at $\mathrm{pH} 7$ calculated by Innovagen's peptide calculator were 22.0 and 14.1 in dApoE-R9 and ApoE-F-R9, respectively). All the ternary complexes with dApoE-R9 or ApoE-F-R9 were approximately $130-150 \mathrm{~nm}$ in size with a monodisperse distribution (polydispersity index: 0.16-0.19) and their $\zeta$-potentials were approximately $36-42 \mathrm{mV}$.

Association of pDNA with cationic liposome and ApoE-R9 peptide. Next, we examined the effect of the charge ratio of the ApoE-R9 peptide in ternary complexes on pDNA association. SYBR ${ }^{\circledR}$ Green I is a DNA/RNA-intercalating agent, the fluorescence of which is markedly enhanced upon binding to pDNA that is not bound to cationic liposomes or ApoE-R9 peptide. In the binary complex of pDNA and ApoE-F-R9, with an increase in the charge ratio (-:+) of pDNA:ApoE-F-R9, ApoE-F-R9 interacted with pDNA, and at a charge ratio (-:+) of 1:3, the fluorescence of SYBR ${ }^{\circledR}$ Green I decreased markedly due to the formation of complexes (Fig. 4A). In contrast, in the binary complex of pDNA and dApoE-R9, already at a charge ratio (-:+) of 1:1, fluorescence decreased markedly. These results indicated that dApoE-R9 interacts more efficiently with pDNA than ApoE-F-R9. Furthermore, in LP-DOTAP/DOPE and LP-DOTAP/Chol lipoplexes, a decrease in fluorescence was observed at a charge ratio (-:+) of 1:4 (Fig. 4B), and in the ternary complexes, fluorescence decreased markedly above a charge ratio (-:+:+) of pDNA:cationic liposome:ApoE-R9 peptide of 1:4:1 regardless of the liposomal formulation, indicating that pDNA lipoplexes and ternary complexes completely bound to pDNA at the charge ratios used in this study. These findings suggested that the interaction between pDNA and cationic liposomes was not affected by the inclusion of ApoE-R9 peptides.

Effect of ApoE-R9 peptide in ternary complexes on in vitro gene transfection. To examine the effect of the ApoE-R9 peptide in ternary complexes on gene expression in hepatic cells, the ternary complexes were added into HepG2 cells. The inclusion of dApoE-R9 or ApoE-F-R9 into LP-DOTAP/DOPE lipoplexes significantly increased transfection activity in HepG2 cells with increasing amounts of ApoE-R9 peptide. Ternary complexes with dApoE-R9 and ApoE-F-R9 exhibited 7.5- and 3.8-fold higher expression in the cells, respectively, than pDNA lipoplexes without ApoE-R9 peptide, when the ternary complexes were prepared at a charge ratio (-:-:+) of 1:4:3 (Fig. 5). However, the inclusion of ApoE-R9 peptide 
A

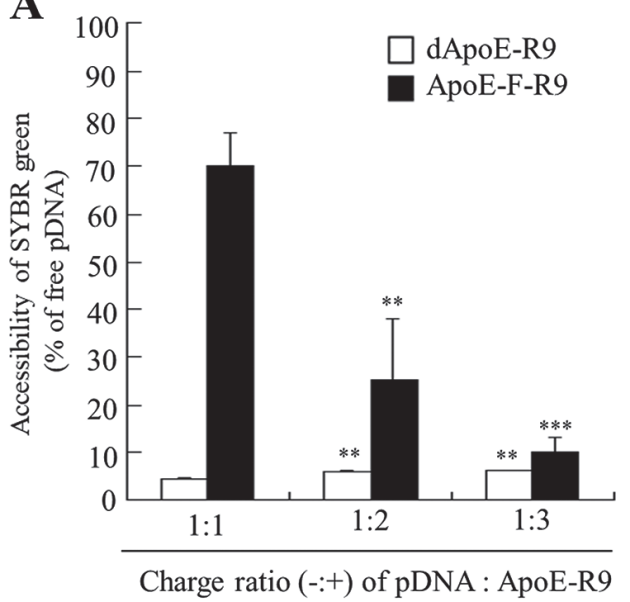

B

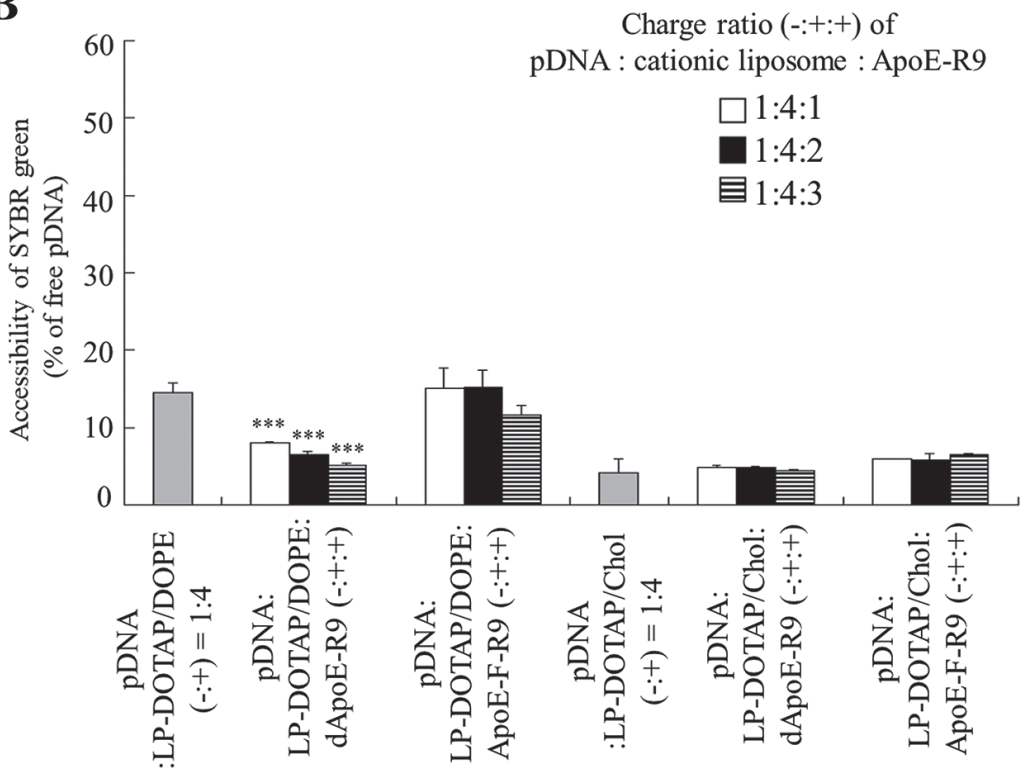

Figure 4. Association of pDNA with ApoE-derived peptide and cationic liposomes as determined via an exclusion assay using SYBR ${ }^{\circledR}$ Green I Nucleic Acid Gel Stain. (A) Binary complexes of pDNA and ApoE-R9 peptide were formed at various charge ratios (-:+) from 1:1-1:3. ${ }^{* *} \mathrm{P}<0.01$ and ${ }^{* * * *} \mathrm{P}<0.001$ vs. the binary complexes of dApoE-R9 or ApoE-F-R9 at a charge ratio (-:+) of 1:1. (B) pDNA lipoplexes were prepared by mixing pDNA with cationic liposomes (LP-DOTAP/DOPE or LP-DOTAP/Chol) at a charge ratio (-:+) of 1:4. Ternary complexes of pDNA, cationic liposomes and ApoE-R9 peptide were formed at various charge ratios (-:+:+) from 1:4:1 to 1:4:3. As a control, the value of fluorescence obtained after the addition of free pDNA solution was set as $100 \%$. The quantity of pDNA available to interact with the $\mathrm{SYBR}^{\circledR}$ Green I is expressed as a percentage of the control. ${ }^{* * *} \mathrm{P}<0.001$ vs. the LP-DOTAP/DOPE lipoplexes. Data are presented as the mean + standard deviation ( $\mathrm{n}=3$ ). pDNA, plasmid DNA; ApoE, apolipoprotein E; LP, liposome; DOTAP, 1,2-dioleoyl-3-trimethylammonium-propane methyl sulfate salt; DOPE, 1,2-dioleoyl-sn-glycero-3-phosphoethanolamine.

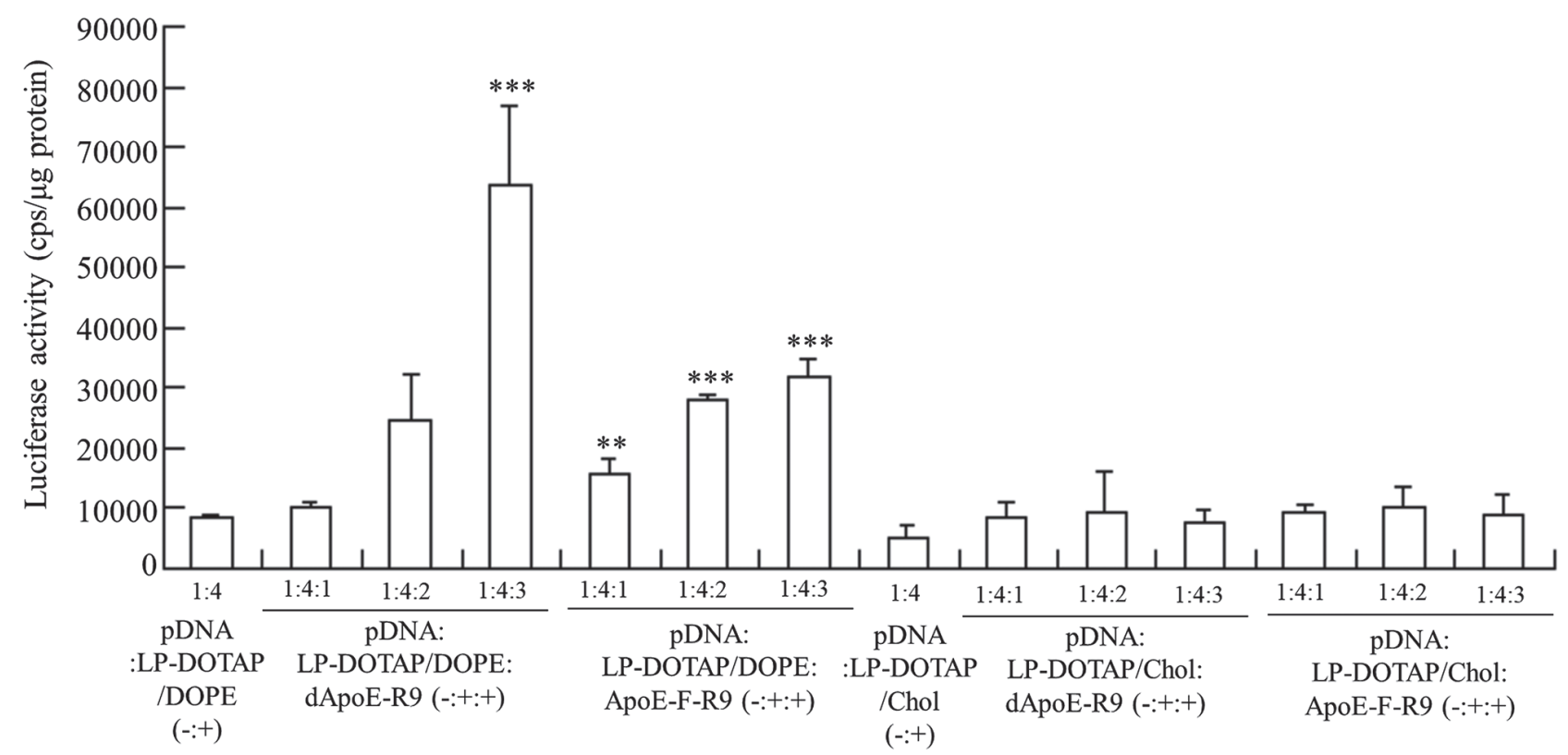

Figure 5. Effect of charge ratio (-:+:+) of pDNA, cationic liposome and ApoE-R9 peptide on the luciferase activity of HepG2 cells at 24 h after transfection with the ternary complex. pDNA lipoplexes were prepared by mixing pCMV-Luc with LP-DOTAP/Chol or LP-DOTAP/DOPE at a charge ratio (-:+) of 1:4. Ternary complexes of pCMV-Luc, cationic liposome and ApoE-R9 peptide were prepared at charge ratios (-:-:+) from 1:4:1-1:4:3. Data are presented as the mean + standard deviation $(\mathrm{n}=3){ }^{* *} \mathrm{P}<0.01$ and ${ }^{* * *} \mathrm{P}<0.001$ vs. LP-DOTAP/DOPE lipoplexes. pDNA, plasmid DNA; ApoE, apolipoprotein E; LP, liposome; DOTAP, 1,2-dioleoyl-3-trimethylammonium-propane methyl sulfate salt; Chol, cholesterol; DOPE, 1,2-dioleoyl-sn-glycero-3-phosphoethanolamine.

into LP-DOTAP/Chol lipoplexes did not increase transfection activity. Furthermore, to examine the effect of the ApoE-R9 peptide in binary complexes on gene expression in HepG 2 cells, binary complexes were added into HepG2 cells. However, the binary complexes of pDNA with dApoE-R9 or
ApoE-F-R9 did not induce high gene expression in the cells (Fig. 6A) compared with their ternary complexes (Fig. 5). This indicated that formation of ternary complex was necessary for efficient pDNA transfer into hepatic cells by ApoE-R9 peptide. Moreover, to investigate the effect of the ApoE-R9 peptide in 
A

HepG2

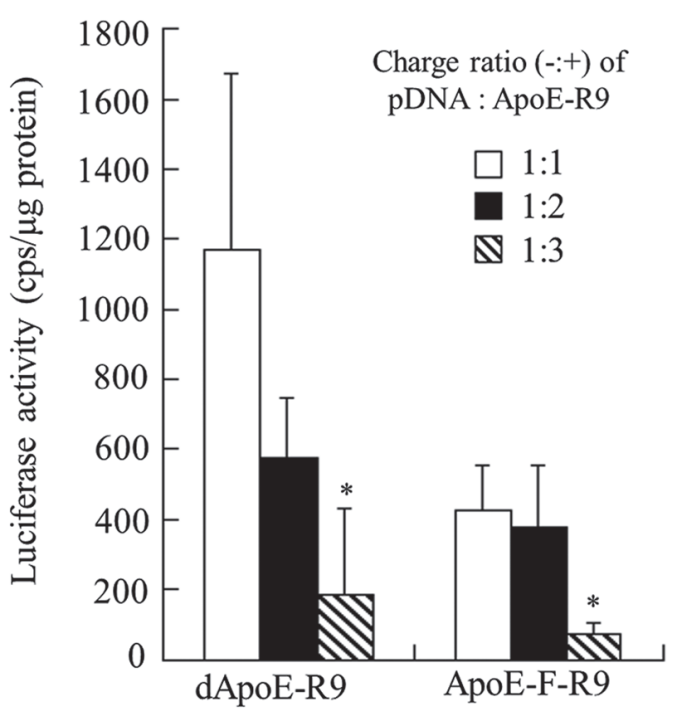

B

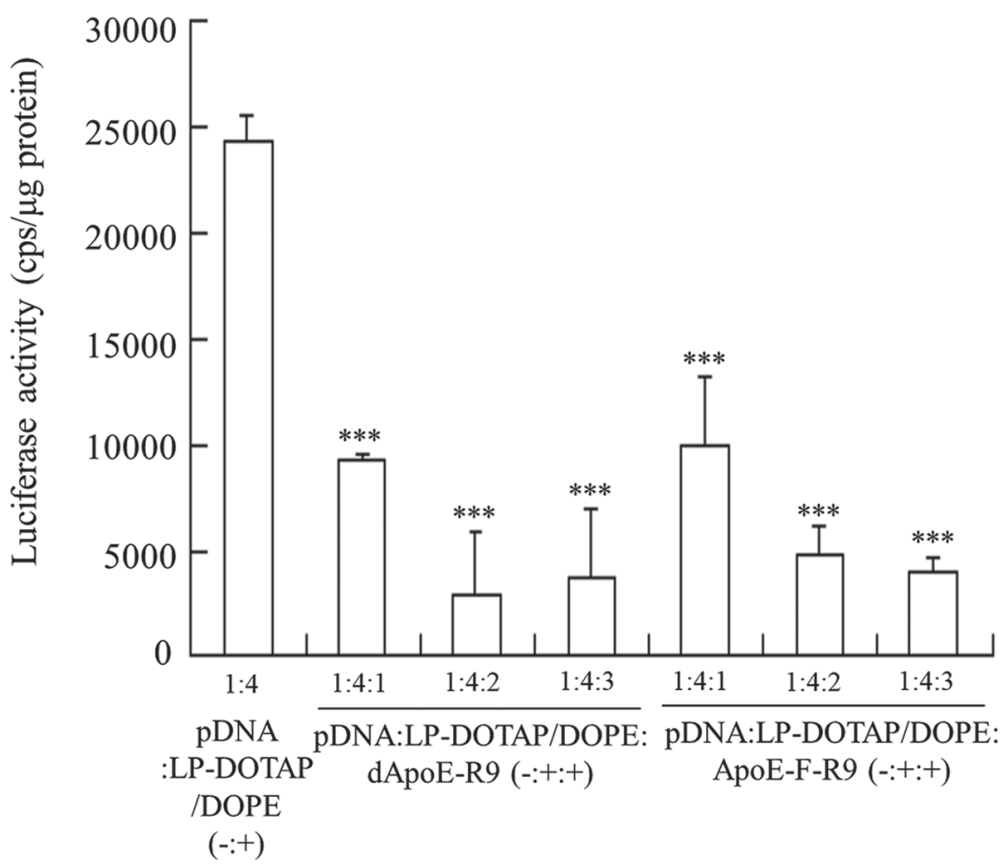

Figure 6. Luciferase activity in HepG2 cells 24 h after transfection with binary complexes of pDNA and ApoE-R9 peptide, and in A549 cells 24 h after transfection with ternary complexes. (A) binary complexes were prepared by mixing pCMV-Luc with dApoE-R9 or ApoE-F-R9 at charge ratios (-:+) from 1:1-1:3. ${ }^{*}$ P<0.05 vs. binary complexes of dApoE-R9 or ApoE-F-R9 at a charge ratio (-:+) of 1:1. (B) pDNA lipoplexes were prepared by mixing pCMV-Luc with cationic liposomes (LP-DOTAP/DOPE or LP-DOTAP/Chol) at a charge ratio (-:+) of 1:4. Ternary complexes of pCMV-Luc, cationic liposome, and ApoE-R9 peptide were prepared at charge ratios (-:+:+) from 1:4:1-1:4:3. ${ }^{* * *} \mathrm{P}<0.001$ vs. LP-DOTAP/DOPE lipoplexes. Data are presented as the mean + standard deviation ( $\mathrm{n}=3$ ). pDNA, plasmid DNA; ApoE, apolipoprotein E; LP, liposome; DOTAP, 1,2-dioleoyl-3-trimethylammonium-propane methyl sulfate salt; DOPE, 1,2-dioleoyl-sn-glycero-3-phosphoethanolamine; Chol, cholesterol.

ternary complexes on gene expression in non-hepatic cells, the ternary complexes were added to A549 cells, which express the LDL receptor at lower levels than HepG2 cells (data not shown). As the result, the ternary complexes did not increase the transfection activity in A549 cells by inclusion of dApoE-R9 or ApoE-F-R9 (Fig. 6B), suggesting that the ternary complexes with ApoE-R9 peptide improve gene expression in hepatic cells. In particular, dApoE-R9 has repeated binding domains for the LDL receptor; therefore, it may exhibit better transfection efficiency in hepatic cells in the ternary complexes than ApoE-F-R9.

Cytotoxicity by ternary complex. To examine the effect of the ApoE-R9 peptide in ternary complexes on cytotoxicity, we investigated cell viabilities at $24 \mathrm{~h}$ after transfection into HepG2 cells with LP-DOTAP/DOPE lipoplexes or ternary complexes. LP-DOTAP/DOPE lipoplexes exhibited only very limited cytotoxicity (Fig. 7), and the inclusion of dApoE-R9 or ApoE-F-R9 into LP-DOTAP/DOPE lipoplexes did not increase cytotoxicity.

Gene expression in the liver after injection of ternary complexes into mice. To investigate the effect of ApoE-R9 peptide in ternary complexes on gene expression in the liver, we injected ternary complexes with ApoE-R9 peptide intravenously into mice. Here, we decided to use dApoE-R9, because ternary complexes with dApoE-R9 exhibited higher gene expression in HepG2 cells than those with ApoE-F-R9 (Fig. 5). Ternary complexes were prepared at a charge ratio (-:+:+) of

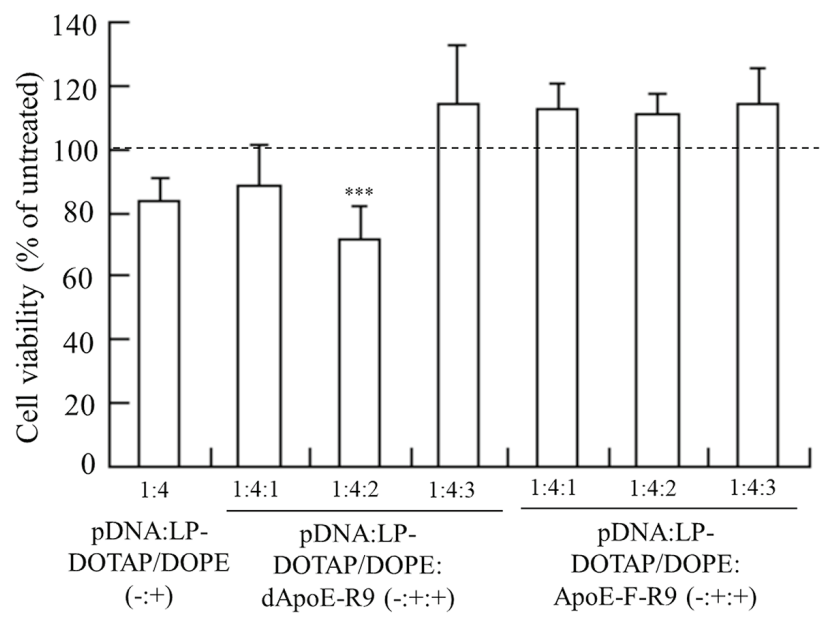

Figure 7. Cell viability $24 \mathrm{~h}$ after transfection with pDNA lipoplexes and ternary complexes in HepG2 cells. pDNA lipoplexes were prepared by mixing pDNA with LP-DOTAP/DOPE at a charge ratio (-:+) of $1: 4$ and ternary complexes were prepared by mixing pDNA with LP-DOTAP/DOPE and the ApoE-R9 peptide at charge ratios (-:+:+) from 1:4:1-1:4:3. Data are presented as the mean + standard deviation $(n=4-6)$. ${ }^{* * * *} \mathrm{P}<0.001$ vs. untreated cells. pDNA, plasmid DNA; LP, liposome; DOTAP, 1,2-dioleoyl-3-trimethylammonium-propane methyl sulfate salt; DOPE, 1,2-dioleoyl-sn-glycero-3-phosphoethanolamine; ApoE, apolipoprotein E.

pDNA:cationic liposomes:dApoE-R9 of 1:4:3. Injection of LP-DOTAP/Chol lipoplexes induced gene expression mainly in the lungs (Fig. 8). In contrast, injection of the ternary complexes with LP-DOTAP/Chol and dApoE-R9 showed 


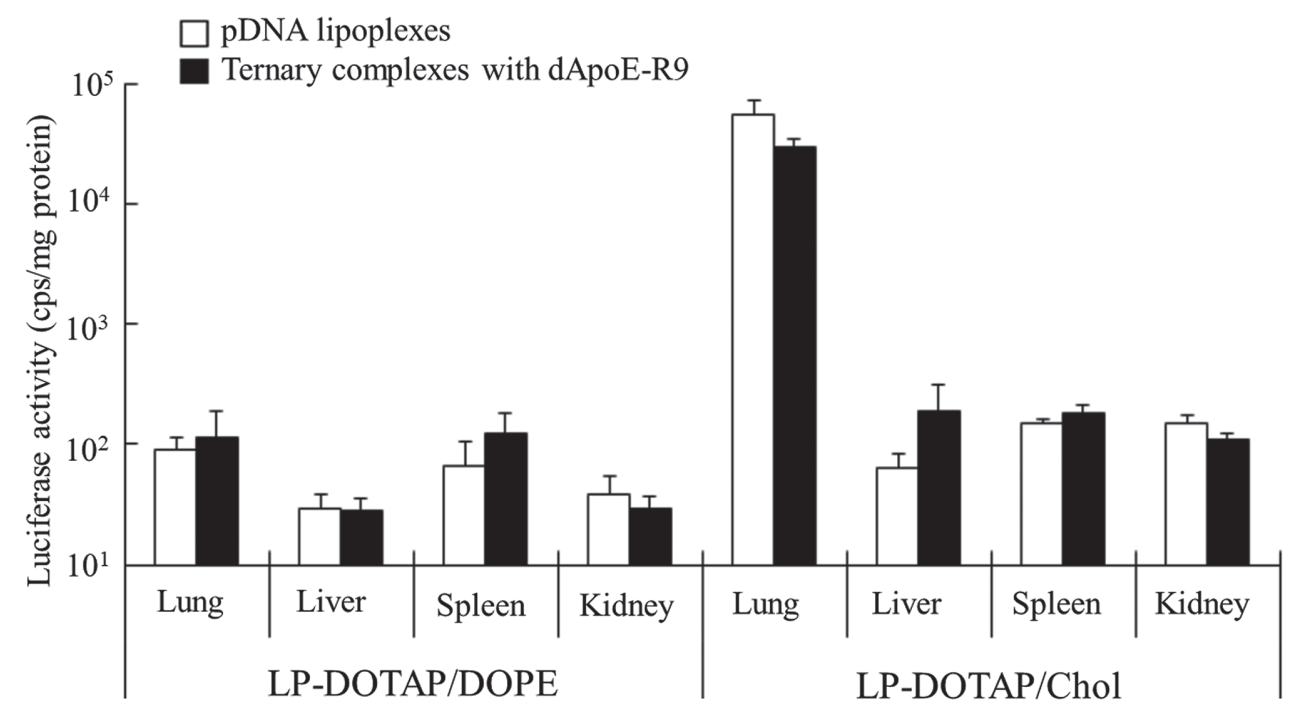

Figure 8. Luciferase activities at $24 \mathrm{~h}$ after intravenous administration of pDNA lipoplexes and ternary complexes into mice. pDNA lipoplexes were prepared by mixing pCMV-Luc with cationic liposomes (LP-DOTAP/DOPE or LP-DOTAP/Chol) at a charge ratio (-:-) of 1:4. Ternary complexes were prepared by mixing pCMV-Luc with cationic liposomes and dApoE-R9 at a charge ratio (-:+:+) of 1:4:3. The pDNA lipoplexes or ternary complexes with $30 \mu \mathrm{g}$ of pCMV-Luc were administered intravenously via the lateral tail vein into mice. The difference of luciferase activity between pDNA lipoplexes and ternary complexes with dApoE-R9 was not statistically significant in any tissue. Data are presented as the mean + standard deviation (n=3). pDNA, plasmid DNA; LP, liposome; DOTAP, 1,2-dioleoyl-3-trimethylammonium-propane methyl sulfate salt; DOPE, 1,2-dioleoyl-sn-glycero-3-phosphoethanolamine; Chol, cholesterol; ApoE, apolipoprotein E.

2-fold lower expression in the lungs and 3-fold higher expression in the liver, although the changes were not significant. These results indicated that the inclusion of dApoE-R9 into the complexes improved the uptake of pDNA by hepatocytes after intravenous injection. However, LP-DOTAP/DOPE lipoplexes did not induce high gene expression in any organs, and the inclusion of dApoE-R9 into LP-DOTAP/DOPE lipoplexes did not increase gene expression in the liver (Fig. 8). These results indicate that the optimal in vivo liposomal formulation of ternary complexes with ApoE-R9 peptide for pDNA transfection differs from the in vitro one. Here, we confirmed that ApoE-derived peptides could increase transfection activity of ternary complexes in HepG2 cells (tumor cells) (Fig. 5) and mouse liver (Fig. 8). However, it will be important to investigate the differences between normal and tumor cells in the ability to bind ternary complexes. Therefore, the transfection ability of ternary complexes to primary hepatic cells should be examined in the future study.

In this study, ternary complexes with LP-DOTAP/Chol induced higher gene expression in mice than those with LP-DOTAP/DOPE, indicating that neutral helper lipid in the liposomal formulation strongly affected in vivo transfection activity. Generally, in in vitro transfection with pDNA lipoplexes, DOPE is often used as a neutral helper lipid in liposomal formulation, because DOPE is thought to improve transfection efficiency by destabilizing the endosomal membrane (28), thereby facilitating the release of pDNA into the cytoplasm.InDOTAP-based cationic liposomes, it has been reported that the in vitro transfection efficiency was mainly influenced by liposomal formulation, and the DOTAP/DOPE ratio determined transfection efficiency (29), suggested that DOPE is an important component of cationic liposomes in in vitro transfection. Therefore, in in vitro transfection of the ternary complexes, with an increase in cellular uptake with the inclusion of dApoE-R9 into the ternary complexes, ternary complexes with LP-DOTAP/DOPE may increase gene expression due to the function of DOPE, compared with those with LP-DOTAP/Chol. Furthermore, Hong et al (27) found that cationic liposomes composed of dimethyl dioctadecyl ammonium bromide (DDAB)/Chol exhibited higher gene expression in the lung after intravenous injection of pDNA lipoplexes than those of DDAB/DOPE, although they did not induce high gene expression in vitro. In addition, Sakurai et al (26) reported that cationic liposomes composed of $N$-[1-(2,3-dioleyloxy)propyl]- $N, N, N$-trimethylammonium chloride (DOTMA)/Chol showed higher gene expression in the lung after intravenous injection of pDNA lipoplexes than DOTMA/DOPE. They speculated that the inclusion of DOPE in the liposomal formulation caused fusion and aggregation of the lipoplexes with erythrocytes in the blood circulation, resulting in a decrease in in vivo transfection activity. Therefore, in in vivo transfection of ternary complexes, the ternary complexes with LP-DOTAP/DOPE may not exhibit strong transfection activities in any organs, compared with LP-DOTAP/Chol. In the in vivo transfection of ternary complexes with ApoE-R9 peptide, LP-DOTAP/Chol may be more suitable as a liposomal carrier than LP-DOTAP/DOPE, although they exhibited high gene expression in the lung. Further studies should be performed to examine liposomal formulations to decrease gene expression in the lungs by decreasing the positive charge in ternary complexes and increase expression in the liver using ApoE-R9 peptide after intravenous injection. In addition, for the clinical application of the ternary complexes with ApoE-R9 peptide, toxicity is an important factor. In a future study, toxicity after intravenous injection of the ternary complexes with ApoE-R9 peptide should be examined for the development of a safe pDNA delivery system to the liver. 
In conclusion, we synthesized two types of ApoE-derived peptides, dApoE-R9 and ApoE-F-R9, and prepared ternary complexes of pDNA, cationic liposomes, and ApoE-R9 peptides for effective transfection into hepatic cells. In the in vitro transfection assays, ternary complexes with dApoE-R9 and DOTAP/DOPE liposomes increased gene expression in hepatic cells. In contrast, in in vivo transfection analyses, ternary complexes with dApoE-R9 and DOTAP/Chol liposomes increased gene expression in the liver after intravenous injection. The optimal in vivo liposomal formulation of ternary complexes with ApoE-R9 peptide for pDNA transfection differed from the in vitro one. From these findings, dApoE-R9 may have potential use as a ligand for liver targeting with ternary complexes. This study provides valuable information about liver targeting by ternary complexes for efficient pDNA delivery into the liver.

\section{Acknowledgements}

The authors would like to thank Mr Yuki Yoshiike (Department of Drug Delivery Research, Hoshi University, Tokyo, Japan) for his experimental assistance (intracellular localization and ex vivo imaging of ApoE-derived peptide).

\section{Funding}

This study was funded only by the resources of our department.

\section{Availability of data and materials}

The datasets used and/or analyzed during the current study are available from the corresponding author on reasonable request.

\section{Authors' contributions}

YH conceived and designed the present study. The experiments were primarily performed by $\mathrm{YN}$. $\mathrm{YH}$ and $\mathrm{HO}$ analyzed and interpreted the data. $\mathrm{YH}$ wrote the manuscript. $\mathrm{HO}$ reviewed and edited the manuscript. All authors have read and approved the final manuscript.

\section{Ethics approval and consent to participate}

All animal experiments were conducted in accordance with the 'Guide for the Care and Use of Laboratory Animals' adopted by the Institutional Animal Care and Use Committee of Hoshi University (Tokyo, Japan; accredited by the Ministry of Education, Culture, Sports, Science and Technology of Japan). Ethical approval for the present study was obtained from the Institutional Animal Care and Use Committee of Hoshi University (Permission no. 30-072).

\section{Patient consent for publication}

Not applicable.

\section{Competing interests}

The authors declare that they have no competing interests.

\section{References}

1. Aravalli RN, Belcher JD and Steer CJ: Liver-targeted gene therapy: Approaches and challenges. Liver Transpl 21: 718-737, 2015.

2. Wu J, Nantz MH and Zern MA: Targeting hepatocytes for drug and gene delivery: Emerging novel approaches and applications. Front Biosci 7: d717-d725, 2002.

3. Nayerossadat N, Maedeh T and Ali PA: Viral and nonviral delivery systems for gene delivery. Adv Biomed Res 1: 27, 2012.

4. Palaschak B, Herzog RW and Markusic DM: AAV-mediated gene delivery to the liver: Overview of current technologies and methods. Methods Mol Biol 1950: 333-360, 2019.

5. Zhang Y, Bradshaw-Pierce EL, Delille A, Gustafson DL and Anchordoquy TJ: In vivo comparative study of lipid/DNA complexes with different in vitro serum stability: Effects on biodistribution and tumor accumulation. J Pharm Sci 97: 237-250, 2008.

6. Lu C, Stewart DJ, Lee JJ, Ji L, Ramesh R, Jayachandran G, Nunez MI, Wistuba II, Erasmus JJ, Hicks ME, et al: Phase I clinical trial of systemically administered TUSC2(FUS1)-nanoparticles mediating functional gene transfer in humans. PLoS One 7: e34833, 2012

7. Eliyahu H, Servel N, Domb AJ and Barenholz Y: Lipoplex-induced hemagglutination: Potential involvement in intravenous gene delivery. Gene Ther 9: 850-858, 2002.

8. Simberg D, Weisman S, Talmon Y, Faerman A, Shoshani T and Barenholz Y: The role of organ vascularization and lipoplex-serum initial contact in intravenous murine lipofection. J Biol Chem 278: 39858-39865, 2003.

9. Pathak A, Vyas SP and Gupta KC: Nano-vectors for efficient liver specific gene transfer. Int J Nanomedicine 3: 31-49, 2008.

10. Getz GS and Reardon CA: Apoprotein E and reverse cholesterol transport. Int J Mol Sci 19: 3479, 2018.

11. Fazio S, Linton MF and Swift LL: The cell biology and physiologic relevance of ApoE recycling. Trends Cardiovasc Med 10: 23-30, 2000.

12. Mortimer BC, Beveridge DJ, Martins IJ and Redgrave TG: Intracellular localization and metabolism of chylomicron remnants in the livers of low density lipoprotein receptor-deficient mice and apoE-deficient mice. Evidence for slow metabolism via an alternative apoE-dependent pathway. J Biol Chem 270: 28767-28776, 1995.

13. Rensen PC, Schiffelers RM, Versluis AJ, Bijsterbosch MK, Van Kuijk-Meuwissen ME and Van Berkel TJ: Human recombinant apolipoprotein E-enriched liposomes can mimic low-density lipoproteins as carriers for the site-specific delivery of antitumor agents. Mol Pharmacol 52: 445-455, 1997.

14. Yan X, Kuipers F, Havekes LM, Havinga R, Dontje B, Poelstra K, Scherphof GL and Kamps JA: The role of apolipoprotein E in the elimination of liposomes from blood by hepatocytes in the mouse. Biochem Biophys Res Commun 328: 57-62, 2005.

15. Tamaru M, Akita H, Nakatani T, Kajimoto K, Sato Y, Hatakeyama $\mathrm{H}$ and Harashima $\mathrm{H}$ : Application of apolipoprotein E-modified liposomal nanoparticles as a carrier for delivering DNA and nucleic acid in the brain. Int $\mathrm{J}$ Nanomedicine 9: 4267-4276, 2014

16. Re F, Cambianica I, Zona C, Sesana S, Gregori M, Rigolio R, La Ferla B, Nicotra F, Forloni G, Cagnotto A, et al: Functionalization of liposomes with ApoE-derived peptides at different density affects cellular uptake and drug transport across a blood-brain barrier model. Nanomedicine 7: 551-559, 2011.

17. Sauer I, Dunay IR, Weisgraber K, Bienert M and Dathe M: An apolipoprotein E-derived peptide mediates uptake of sterically stabilized liposomes into brain capillary endothelial cells. Biochemistry 44: 2021-2029, 2005.

18. Hülsermann U, Hoffmann MM, Massing U and Fricker G: Uptake of apolipoprotein E fragment coupled liposomes by cultured brain microvessel endothelial cells and intact brain capillaries. J Drug Target 17: 610-618, 2009.

19. Igarashi S, Hattori Y and Maitani Y: Biosurfactant MEL-A enhances cellular association and gene transfection by cationic liposome. J Control Release 112: 362-368, 2006.

20. Kato M, Hattori Y, Kubo M and Maitani Y: Collagenase-1 injection improved tumor distribution and gene expression of cationic lipoplex. Int J Pharm 423: 428-434, 2012.

21. Hattori Y, Yamasaku H and Maitani Y: Anionic polymer-coated lipoplex for safe gene delivery into tumor by systemic injection. J Drug Target 21: 639-647, 2013. 
22. Hattori Y and Maitani Y: Folate-linked nanoparticle-mediated suicide gene therapy in human prostate cancer and nasopharyngeal cancer with herpes simplex virus thymidine kinase. Cancer Gene Ther 12: 796-809, 2005.

23. Li S, Tseng WC, Stolz DB, Wu SP, Watkins SC and Huang L: Dynamic changes in the characteristics of cationic lipidic vectors after exposure to mouse serum: Implications for intravenous lipofection. Gene Ther 6: 585-594, 1999.

24. Martin B, Sainlos M, Aissaoui A, Oudrhiri N, Hauchecorne M, Vigneron JP, Lehn JM and Lehn P: The design of cationic lipids for gene delivery. Curr Pharm Des 11: 375-394, 2005.

25. Yeeprae W, Kawakami S, Suzuki S, Yamashita F and Hashida M: Physicochemical and pharmacokinetic characteristics of cationic liposomes. Pharmazie 61: 102-105, 2006.

26. Sakurai F, Nishioka T, Saito H, Baba T, Okuda A, Matsumoto O, Taga T, Yamashita F, Takakura Y and Hashida M: Interaction between DNA-cationic liposome complexes and erythrocytes is an important factor in systemic gene transfer via the intravenous route in mice: The role of the neutral helper lipid. Gene Ther 8: 677-686, 2001
27. Hong K, Zheng W, Baker A and Papahadjopoulos D: Stabilization of cationic liposome-plasmid DNA complexes by polyamines and poly(ethylene glycol)-phospholipid conjugates for efficient in vivo gene delivery. FEBS Lett 400: 233-237, 1997.

28. Du Z, Munye MM, Tagalakis AD, Manunta MD and Hart SL: The role of the helper lipid on the DNA transfection efficiency of lipopolyplex formulations. Sci Rep 4: 7107, 2014.

29. Kim BK, Hwang GB, Seu YB, Choi JS, Jin KS and Doh KO: DOTAP/DOPE ratio and cell type determine transfection efficiency with DOTAP-liposomes. Biochim Biophys Acta 1848: 1996-2001, 2015.

(i) (-) This work is licensed under a Creative Commons Attribution-NonCommercial-NoDerivatives 4.0 International (CC BY-NC-ND 4.0) License. 